\title{
Shared Leadership: A Primer and Teaching Recommendations for Educators
}

\author{
Angelina V. Kalinovich \\ Graduate Student, Masters of Business Administration \\ Seattle University \\ Jennifer A. Marrone, PhD \\ Associate Professor, Management \\ Seattle University
}

\begin{abstract}
In this Idea Brief, we review the literature on shared leadership (SL) and provide specific ideas for including SL in curriculum. SL is an emergent team property whereby leadership functions are distributed among the team's members. Though relatively new to the groups and teams literatures, its strong and positive impact on performance has been well established in extant studies. To encourage and enable its inclusion in future leadership courses, we first provide educators with key information regarding SL conceptualization, measurement, and findings. Next, we offer specific classroom recommendations, including the administration of a SL assessment tool with reflective discussion prompts. We conclude with the anticipated outcomes of implementing our recommendations.
\end{abstract}

\section{Introduction}

Shared leadership (SL) reflects the extent to which leadership influence is distributed across the members of a collective as opposed to leadership remaining centralized within one powerful figure (Carson, Tesluk, \& Marrone, 2007). At least 13 team studies and two metaanalyses have been published in top-tier academic journals on SL. This research was conducted across varying work environments, team types, hierarchical structures, and distinct leadership influence types. Collectively, this body of work strongly supports that SL is a significant and positive predictor of team performance and effectiveness (Nicolaides et al., 2014; Zhang, Waldman \& Wang, 2012). The increased scholarly attention to this construct, and its positive links to performance, strongly suggest that including SL in leadership courses is important and impactful.

It is necessary for educators to understand the nuances of extant SL findings in order to present and to disseminate related, current knowledge to students. For instance, defining what constitutes SL is essential foundational material for educators to understand and communicate to students. Additionally, knowledge of the development of SL in teams and how SL exerts such strong influence on performance is critical information for those wishing to implement SL in their future team settings. Finally, sharing information on key moderating variables that enhance 
or hinder the relationships between SL and team outcomes provides students with practical ideas for maximizing team performance at work and at school.

To provide this needed information, we first review and summarize extant SL research. We discuss commonly-asked student questions and review how the SL research helps educators to answer and use such questions to encourage reflective in-class discussions. Then we provide specific teaching recommendations, including an impactful SL assessment tool, and we discuss the implementation and anticipated outcomes of our teaching ideas.

To conduct our review, we searched these top management and leadership journals for studies pertaining to SL: Academy of Management Journal, Academy of Management Review, Administrative Science Quarterly, Group and Organization Management, Journal of Applied Psychology, Journal of Management, Organizational Behavior and Human Decision Processes, Personnel Psychology, Small Group Research, and The Leadership Quarterly. Additionally, we examined the references in the Wang, Waldman, and Zhang (2014) meta-analysis to ensure that we did not miss any key empirical studies. Though our literature review was not exhaustive, we believe that the studies we discuss here demonstrate the range of investigations on SL, embody the most rigorous and impactful studies on SL, and provide sufficient background for educators to include SL in the classroom.

\section{Defining SL for Students}

Foundational questions routinely asked by students include: "what is shared leadership?" and "how does this differ from participation by all team members or from teamwork?" The research we reviewed provides answers to these questions.

In regards to the first question, we observed that the definition by Drescher, Korsgaard, Welpe, Picot, and Wigand (2014) summarizes the most common understanding of SL by academic scholars. These authors define SL as "an emergent property of a group where leadership functions are distributed among group members" (p. 772). Teams with high SL rely on many members within their team to execute leadership functions as opposed to one formally or informally appointed leader.

Yet SL scholars differ when it comes to the type of leadership influence that is shared. The research discusses three broad types of leadership influence (Wang et al., 2014): 1) traditional SL influence, 2) contemporary SL influence, and 3) overall SL influence. Traditional SL influence is indicated by team members exerting influence on their team through taskoriented direction and transactional forms of leadership. Traditional SL influence focuses on exchanges and maintaining the status quo. Contemporary SL influence is characterized by teamvisionary, authentic, and transformational leadership behaviors (Wang et al., 2014). Contemporary SL influence emphasizes change and development. Overall SL influence is assessed by asking team members to identify the extent to which the team relies on each individual in the team for leadership. The content of leadership is intentionally unspecified; instead, members rely on their own inherent understanding of leadership. Overall SL influence is supported by functional team leadership theory, which suggests that team leaders exert influence 
by filling whatever functions are currently needed, such as providing direction, motivation, or support to the team (e.g., Carson et al., 2007).

Irrespective of SL influence type, scholars agree that SL is an emergent team property or characteristic, not a behavior. This distinction is very helpful when discussing the nature of SL with students. SL, like other emergent states such as collective team efficacy or psychological safety, are characteristics representative of what a team is or a property that the team has. SL is a collective, team property that is rooted in particular leadership-emergence processes occurring over time. As team members interact, process information collectively, and use cues in their social environment, their perceptions coalesce concerning what leadership is, how leadership is enacted in and by the team, and how to best collectively rely on the exercise of leadership by team members. See Hmeileski, Cole, and Baron (2012) for further discussion.

Emergent team properties like SL thus originate in, but are distinct from, the interactions of its group members. Participation by team members on team tasks or by voicing opinions on team direction are not examples of SL. These interactions probably are closely-related antecedent conditions that help lead to the emergence of SL as a property. Scholars agree that these interactions and other closely-related constructs (e.g., self-managing teams, team empowerment, and cooperation) may precede or follow SL, but they do not equate to (or necessarily involve) active leadership influence that is widely distributed in a team. For example, research as shown "only moderate correlation between SL and cooperation or helping" (Carson et al. 2007; p. 1221).

\section{Studying SL and its Performance Effects}

SL's strong performance effects are perhaps the most compelling aspect of this construct. Regardless of SL leadership influence type (traditional, contemporary, or overall), teams that develop higher SL significantly outperform teams with lower SL. In the meta-analysis by Wang et al. (2014), traditional SL influence had the lowest, though still significant, effect on team performance when compared to the other SL influence types. Positive team performance or productivity is the most commonly studied consequence of SL (e.g., Carson et al., 2007; Drescher et al., 2014; Hannah, Walumbwa, \& Fry, 2011; Nicolaides et al., 2014; Small \& Rentsch, 2010). The results of two meta-analyses and other studies that examined the relative influence of SL versus vertical leadership forms (i.e., a single, dominant leader) confirm that SL explains unique variance in performance that is above and beyond that of vertical leadership. See, for examples: Ensley, Hmieleski, and Pearce (2006), Nicolaides et al. (2014), and Wang et al. (2014). Both meta-analyses also found that the performance effects of SL are consistent across academic and organizational contexts and within varying team types. This research should provide educators pervasive evidence supporting the practical relevance of teaching SL and rich, diverse examples to illustrate SL and generate ideas for teaching it in the classroom.

Two, primary team types were discussed in the SL research we reviewed: 1) existing professional and student work teams, and 2) experimental student teams assigned to business simulations. These team types are discussed below. (A summary chart of all studies reviewed is available upon email request to marronej@ seattleu.edu). 
Existing Professional and Student Work Teams. Nine of the studies we reviewed examined SL within existing professional and student work teams. Teams ranged from two to seven members and existed in a variety of environments (e.g., virtual teams, new ventures, classroom team projects). All studies reviewed were supportive of the team performance benefits associated with SL. Furthermore, two of these studies examined top management teams (TMTs) and found that SL leads to higher firm performance and growth (Ensley et al., 2006; Hmieleski et al, 2012). In studies of existing teams, the authors most often utilized a survey approach, asking team members to rate the extent to which the team's members exercised leadership influence. Traditional, contemporary, and overall SL leadership influence types have all been examined, revealing largely consistent results.

Experimental Student Teams Engaged in Business Simulations. We reviewed four studies related to business simulations. Three of these studies examined the performance effects of SL on university student teams engaged in business simulations as part of a classroom learning experience: Boies, Lvina, and Martens (2010), Mathieu, Kukenberger, D'Innocenzo, and Reilly (2015), and Small and Rentsch (2010). For these three studies, teams generally ranged from two to five members that were assigned to simulations in business courses (e.g., strategic management), and studied in large universities at the undergraduate and/or graduate levels. Often, the students were assigned to "management teams," responsible for making a number of operational and strategic decisions. Researchers used a survey approach that measured SL based on respondents' ratings of each team member's leadership (Mathieu et al., 2015; Small \& Rentsch, 2010) or on respondents' evaluations of the types of SL influence present in their group (Boies et al., 2010). The fourth study we examined (Drescher et al., 2014) was not conducted in the classroom and included three-to-60 member teams. It measured SL based on "the total number of responsibilities granted by the group founders within the group using trace data" (p.775).

Importantly, despite the concerns about generalizing classroom experiences to professional contexts, three of these four studies yielded the same consistent positive performance effects of SL as compared to existing work team studies. The exception, Boies et al.'s (2010) study, found transformational SL predicted team potency, but not team performance. The meta-analyses by Nicolaides et al. (2014) and Wang et al. (2014) noted no differences in performance effects across team type and only minimal differences across measurement approaches.

\section{Understanding Key Antecedents and Consequences of SL}

The research we reviewed also provides answers to a third, commonly-asked student question: "how can we foster SL in our teams?" Generally, the antecedents of SL include: trust (Drescher et al., 2014), authenticity (Hannah et al., 2011), collectivism (Small \& Rentsch, 2010), high interdependence (Nicolaides et al., 2014), and external leader coaching and support (Carson et al., 2007). More specifically, to facilitate SL, team members must view their tasks and responsibilities as interdependent and their performance as a collective outcome. SL also requires team members to have an accurate understanding of each other's skills and abilities. This fosters trust among team members in regards to each other's competencies (Small \& Rentsch, 2010). Finally, Carson et al. (2007) demonstrated the importance of supportive external 
leaders who help teams develop self-management, initiative, and autonomy. Interestingly, supportive external leadership was necessary only when the team's internal conditions did not support SL. Alternatively, when team members provided one another with social support, encouraged "voice," and established a shared purpose, they significantly enhanced SL and team performance.

\section{Mediating and Moderating Conditions}

There are a few, relatively recent studies investigating the effects of mediating and moderating conditions on SL's relationship with team performance. This section describes our brief review of these studies, and it includes information we recommend that educators share with their students.

In their 2014 meta-analysis, Nicolaides et al. (2014) concluded that SL contributes to performance through the enactment of a key motivational emergent state: team confidence (p.13). This conclusion was also supported by Sivasubramanium et al. (2002), who found that the effect of SL on team performance was mediated by group potency beliefs (p. 87). They suggested that the direct effect of SL may not be as potent as the mediating effect of higher team confidence, which may account for more of SL's effect on team performance. See also Hmieleski et al. (2012) for additional evidence.

Another meta-analysis completed by Wang et al. (2014) provided strong evidence that the complexity of task work serves as an important moderator between SL and team performance. The results suggested that when work is more knowledge-based and interdependent, the relationship between SL and performance outcomes is stronger. When work is less complex, the relationship between SL and performance outcomes is weaker, though SL still positively enhances team performance. We recommend sharing this information student teams: investing time and effort in developing SL is likely to yield the highest returns when teams face complex tasks.

Several moderating conditions have been examined and not been found to be significant. In the two meta-analyses, SL's positive relationship with team performance was not contingent on team type or setting (Nicolaides et al., 2014; Wang et al., 2014). In their 2014 study of virtual teams, Hoch and Kozlowski found that "the association between shared team leadership and team performance was not affected by the degree of virtuality" (p. 398).

\section{Unique and Contradictory Findings}

In this last part of our review, we highlight unique and contradictory findings that emerge across key empirical studies of SL. Educators designing a stand-alone course on SL may have ample time and/or interest to discuss these interesting findings with students.

Hoch, Pearce, and Welzel (2010) found a three-way interaction suggesting that "shared leadership (SL) was positively related to team performance only when both age diversity and coordination were low, thereby showing that there are compensating effects" (p. 112). The results are surprising, because coordination, in the form of interdependence, has been proposed 
as an antecedent to SL rather than as a moderating condition (Nicolaides et al., 2014). The role of team coordination needs further examination.

A comparison of one meta-analysis to a second meta-analysis and other studies highlights an important and contradictory finding. In their meta-analysis, Nicolaides et al. (2014) concluded "that as team tenure increases, SL validities decrease" (p. 13). This conclusion is contradicted by another meta-analysis and two other studies. In their meta-analysis, Wang et al. (2014) infer that time and increased familiarity among team members would "enhance the sharedness of leadership in a team" (p. 37). Additionally, in their 2010 study, Small and Rentsch found that that trust is a significant antecedent of SL. Given that trust develops over time and with increased familiarity, this appears to contradict the assertion that SL decreases with team tenure. Finally, Mathieu et. al. (2015) found that SL evolves and remains to be a positive influence on team cohesion over time. Nicolaides et al. (2014) explain their findings by asserting that "team members cannot sustain the sharing of leadership over a long period of time because of a likely emergence of power struggles and process conflict" (p. 13). Moreover, they note that team membership may change over time and thereby alter the leadership dynamic of the group.

\section{Experiencing SL in the Classroom}

SL Assessment Tool. We move next to offering a specific teaching recommendation that provides students with an experiential opportunity to experience, assess, and more deeply comprehend the nature and operations of SL. In particular, we recommend that educators use a SL assessment tool adapted from Carson et al. (2007) to enable students to explore SL in their classrooms.

In their 2007 study, Carson et al. used a social network approach (SNA) for conceptualizing and measuring SL. SNA examines the relational structures present across individuals and within collectives. Using the SNA approach for assessing SL in the classroom should provide helpful visual diagrams through which students can see the pattern and level of leadership influence in their own teams and compare these elements to those of other teams.

We think using the adapted tool can create a rich experiential learning opportunity for students engaged in a team project as part of their course work. Students could also be instructed to use the tool with other professional and classroom teams and reflect on those results.

Administering the Assessment and Scoring Team Results. We recommend administering the SL assessment near the midpoint of the course, a time when teams are motivated to reflect and are most open to interventions (Hackman, 2002). However, if student anxiety seems too high or direction too unclear at the midpoint, administering the SL assessment after three-quarters of the course is completed may be more effective. This later timing also may allow for assessing the team's antecedents conditions at the course midpoint using a separate survey. See Carson et al. (2007)'s study for survey items related to antecedent conditions.

To administer the tool and generate the visual diagrams, a short survey needs to first be distributed. The survey asks each team member to rate his/her teammates on a single item, "to what extent does this team rely on each individual for leadership?" Ratings are based on this 
five-point Likert-type scale: " $1=$ not at all; $2=$ to a little extent; $3=$ to some extent; $4=$ to a great extent; $5=$ to a very great extent." Second, after collecting the responses, educators then calculate a SL score for each team in accordance with Carson et al's (2007) method: "summing all values (here, the team members' ratings of each other's leadership) and then dividing that score by the total number of possible ties, or relationships across, members" (p. 1225). Higher numbers indicate higher team SL. If desired, the educator can create and distribute individual leadership scores for each team member by averaging all members' ratings of the individual's leadership influence on the team. The last step is to create and distribute leadership sociograms for each team. To do so, first, dichotomize the original scores by assigning a 1 to ratings of 4 or 5 and assigning a 0 to ratings of 3 or less. Next, plot all relationships in which one team member rates another as a source of leadership (i.e., those responses coded as 1) as directional arrows between each dyad, thus creating a leadership sociogram. Individual team members are represented by drawing "nodes" or circles within the sociogram and the directional arrows are drawn between the nodes as appropriate. Example sociograms are provided in Carson et al. (2007) on page 1226. To interpret the sociograms, individuals with no arrows drawn toward their nodes were not rated as team leaders by other team members at a raw score level of four or higher. Individuals with no arrows emanating away from their nodes did not rate any of their teammates as team leaders at a raw score level of four or higher.

The SL assessment tool provides quantitative and visual team scores. The quantitative score indicates the level of the team's SL. The visual picture, or sociogram, presents a visual pattern of the team's SL. Three example team SL scores found by Carson et al. were 2.40, 3.15, and 4.90 in their analysis of $59 \mathrm{MBA}$ student teams. These scores represented low, median, and high team SL, respectively. The sociogram associated with the high team SL score showed more bi-directional arrows between more team members than did the sociogram of the low team SL score, which showed few uni-directional arrows to a small subset of team members. Team SL scores and sociograms can be created 'by-hand' using the steps and calculations we provided above. Educators who teach large numbers of student teams or who are interested in SNA more generally may find SNA software useful for automating the process. Two recommended software tools are Organizational Risk Analysis (ORA) and UCINET. More information on these can be found at http://www.casos.cs.cmu.edu/projects/ora/ and https://sites.google.com/site/ucinetsoftware/home, respectively.

The empirical robustness of this tool is supported by the Carson et al. (2007) study, which demonstrated adequate interrater reliability, and by subsequent studies (Mathieu et al., 2015; Wang et al., 2014) which offered evidence of the tool's face validity. We do recommend an important modification to the Carson et al. (2007) method. Specifically, for the purposes of learning and development we suggest that educators include team member names for each diagram. Furthermore, the SL assessment tool can evaluate any of the three types of leadership influence simply by adding and scoring additional leadership behaviors.

Discussing Team Results. Reviewing the team scores and sociograms, and using the discussion questions listed below, should provide students with a deeper understanding of the leadership influence they have or do not have inside their team. Particularly if team member names are revealed as we suggest, it is critical to ensure a safe, nonthreatening environment for discussing team results. To do so, student scores should not affect course grades and should not 
be judged positively or negatively by educators. In addition, educators can distribute and discuss other teams' sociograms at the onset of discussions and point out that most teams have unequal distributions of leadership. Students can also be forewarned that although some students may see their sociograms as self-evident, others may be very surprised by the results. Finally, educators also should highlight that this approach to assessing SL intentionally does not specify a particular type of leadership influence. They may note that modified surveys that reflect traditional or contemporary leadership behaviors may provide different results.

Teams can also compare their SL sociograms with those of other teams (real or fictitious). For example, educators can provide students with example team SL scores and sociograms demonstrating low, average, and high SL team levels. Consideration of the examples should enhance student learning and reflection.

We also recommend that educators discuss some or all of the following questions to encourage student reflection and to deepen learning.

1. Prior to viewing assessment results: What is your prediction of the level (low or high) of SL in your team? Students can draw their own anticipated visual representations to predict the pattern of leadership that has emerged.

2. After viewing assessment results: How do the assessment results compare to your predictions? What similarities and differences surprise you?

3. How does your team's SL score reflect your actual experiences on this team? What factors have helped or hindered the development of SL in your team?

4. Based on the SL sociograms, which team members are relied upon most and least for leadership influence? What leadership functions does your team rely on you to deliver? What leadership functions does your team rely on others to deliver?

5. Is it easier for you to accept leadership influence from your team members or to exert leadership influence on your team members? Why?

6. Is the distribution of leadership across your team's members equitable and just? If not, what distribution would be better?

7. How should team members build mutual trust and influence?

8. What leadership functions are currently not being addressed by the team?

9. How does the presence of an external leader (e.g., an instructor or a manager at work) help or hinder your team's SL? What actions are most important for external leaders who wish to facilitate team SL?

\section{Related Student Learning Activities}

We also recommend that educators assign students to review scholarly readings that showcase the variety of 'real-world' examples of SL. Reviewing academic studies that emphasize that SL leads to higher performance in different professional contexts may heighten student awareness of the relevance of this topic. This may increase student motivation to engage in SL at work and to learn more about SL in the classroom. Importantly, because some students may become overwhelmed by technical language in academic studies, we recommend telling students to focus primarily on these typical sections in the articles: abstract, introduction, theoretical background, hypothesis development, and discussion. As a start, we offer three reading recommendations below. 
In their 2006 study, Ensley et al. sampled 66 TMTs to investigate the effect of SL on new venture performance. Above and beyond the vertical influence of traditional external leaders, the study found compelling and detailed evidence of the unique power of SL in actual work environments. The focus on executive-level management and new venture partners may be of particular interest to graduate students with prior work experience.

In a related study, Hmieleski et al. (2012) investigated shared authenticity as the type of SL influence. The results of their random sample survey of TMTs showed that shared authentic leadership has a positive indirect relationship with firm performance. Collectively with Ensley et al. (2006), these findings demonstrate that the performance effects of SL on business performance are robust in organizational settings and are consistent irrespective of the particular type of leadership influence shared among team members.

Finally, the Carson et al. (2007) study of MBA consulting teams provides compelling evidence of the strong effect of SL on team performance. This study also provides clear discussions of the nature and antecedents of SL. Moreover, it demonstrates using the SL assessment tool we recommended earlier within a student team context and may be especially relatable to students with little or no work experience and/or students who participate in the SL assessment tool as part of their coursework.

\section{Anticipated Outcomes}

Our recommendation to pair an established measure of SL with customizable sociograms should provide students with clear quantitative and rich visual information. Reflections and related readings provide opportunity for additional learning and can aid students in interpreting their SL assessment tool results.

Incorporating SL in the classroom should provide three primary learning outcomes. First, students should gain an advanced understanding of leadership. In particular, learning that SL compares to, or exceeds, external leadership as a driver of team performance is both powerful and surprising. Second, and related to the first, students should increase their capability to create conditions that enhance team performance at school and at work. At a minimum, we expect that students will experience stronger feelings of autonomy and self-determination in achieving the outcomes they desire. Third, students should increase their awareness of their own leadership skills and influence. For example, reviewing their leadership influence in a sociogram can reveal gaps that prompt students to reflect on their capacities to exert leadership and to accept leadership from peers. Reflecting on the conditions that support or hinder SL with classmates can provide students with new strategies for enhancing their team leadership skills. And exploring visual maps of team SL, when coupled with reflective discussions and related readings, should result in sustained learning that carries forward to their future team endeavors.

\section{Conclusion}

This paper provided foundational material and advanced topics regarding SL. It included specific recommendations to educators for incorporating this information in classroom settings. We anticipate that implementating our recommendations will deepen student knowledge of 
leadership, increase student capability to lead teams effectively, and promote greater student awareness of their current leadership skills.

\section{References}

Avolio, B. J., Jung, D. I., Murry, W., \& Sivasbramaniam, N. (1996). Building highly developed teams: Focusing on shared leadership process, efficacy, trust, and performance. In M. M. Beyerlein, D. A. Johnson, \& S. T. Beyerlein (Eds.), Advances in interdisciplinary studies of work teams (pp. 173-209). Greenwich, CT: JAI Press.

Boies, K., Lvina, E., \& Martens, M. L. (2015). Shared leadership and team performance in a business strategy simulation. Journal of Personnel Psychology, 9(4), 195-202. doi: $10.1027 / 1866-5888 / \mathrm{a} 000021$

Carson, J. B., Tesluk, P. E., \& Marrone, J. A. (2007). Shared leadership in teams: An investigation of antecedent conditions and performance. Academy of Management Journal, 50(5), 1217-1234. doi:10.2307/20159921

Drescher, M. A., Korsgaard, M. A., Welpe, I. M., Picot, A., \& Wigand, R. T. (2014). The dynamics of shared leadership: Building trust and enhancing performance. Journal of Applied Psychology, 99(5), 771. doi: 10.1037/a0036474

Ensley, M. D., Hmieleski, K. M., \& Pearce, C. L. (2006). The importance of vertical and shared leadership within new venture top management teams: Implications for the performance of startups. The Leadership Quarterly, 17(3), 217-231. doi:10.1016/j.leaqua.2006.02.002

Hackman, J. R. (2002). Leading teams: Creating conditions for great performances. Boston, MA: Harvard Business School Press.

Hannah, S. T., Walumbwa, F. O., \& Fry, L. W. (2011). Leadership in action teams: Team leader and members' authenticity, authenticity strength, and team outcomes. Personnel Psychology, 64(3), 771-802. doi: 10.1111/j.1744-6570.2011.01225.x

Hmieleski, K. M., Cole, M. S., \& Baron, R. A. (2012). Shared authentic leadership and new venture performance. Journal of Management, 38(5), 1476-1499. doi: $10.1177 / 0149206311415419$

Hoch, J. E., \& Kozlowski, S. W. (2014). Leading virtual teams: Hierarchical leadership, structural supports, and shared team leadership. Journal of Applied Psychology, 99(3), 390. http://dx.doi.org/10.1037/a0030264

Hoch, J. E., Pearce, C. L., \& Welzel, L. (2015). Is the most effective team leadership shared?. Journal of Personnel Psychology, 9(3), 105-116. doi: 10.1027/1866$5888 / \mathrm{a} 000020$ 
Klein, K. J., Ziegert, J. C., Knight, A. P., \& Xiao, Y. (2006). Dynamic delegation: Shared, hierarchical, and deindividualized leadership in extreme action teams. Administrative Science Quarterly, 51(4), 590-621. Retrieved from http://asq.sagepub.com/

Mathieu, J. E., Kukenberger, M. R., D’Innocenzo, L., \& Reilly, G. (2015). Modeling reciprocal team cohesion-performance relationships, as impacted by shared leadership and members' competence. Journal of Applied Psychology, 100(3), 713-734. http://dx.doi.org/10.1037/a0038898

Nicolaides, V. C., LaPort, K. A., Chen, T. R., Tomassetti, A. J., Weis, E. J., Zaccaro, S. J., \& Cortina, J. M. (2014). The shared leadership of teams: A meta-analysis of proximal, distal, and moderating relationships. The Leadership Quarterly, 25(5), 923-942. http://dx.doi.org/10.1016/j.leaqua.2014.06.006

Sivasubramaniam, N., Murry, W. D., Avolio, B. J., \& Jung, D. I. 2002. A longitudinal model of the effects of team leadership and group potency on group performance. Group \& Organization Management, 27(1), 66-96. doi: 10.1177/1059601102027001005

Small, E. E., \& Rentsch, J. R. (2015). Shared leadership in teams. A matter of distribution. Journal of Personnel Psychology, 9(4), 203-211. doi: 10.1027/1866-5888/a000017

Wang, D., Waldman, D. A., \& Zhang, Z. (2014). A meta-analysis of shared leadership and team effectiveness. Journal of Applied Psychology, 99(2), 181. http://dx.doi.org.proxy.seattleu.edu/10.1037/a0034531

Zhang, Z., Waldman, D. A., \& Wang, Z. (2012). A multilevel investigation of leader-member exchange, informal leader emergence, and individual and team performance. Personnel Psychology, 65(1), 49-78. doi: 10.1111/j.1744-6570.2011.01238.x

\section{Author Biographies}

Angelina V. Kalinovich (angelinakalinovich@gmail.com) is a graduate student in the Professional Master of Business Administration program at the Albers School of Business and Economics, Seattle University. Her areas of focus are Leadership Formation and Business Analytics. She received her Bachelor degree in International Studies and Spanish from Seattle University.

Jennifer A. Marrone (marronej@ seattleu.edu) is an associate professor of management at the Albers School of Business and Economics, Seattle University. She received her Ph.D. from the Robert H. Smith School of Business, at the University of Maryland, College Park. Her current research interests include team processes, team performance, and leadership. 